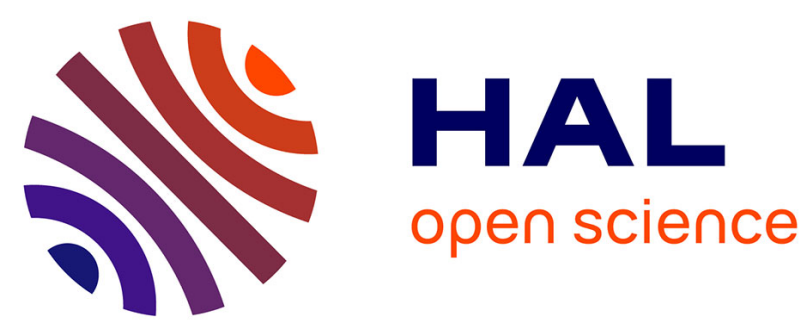

\title{
Fear of novelty: a model of scientific discovery with strategic uncertainty
}

Damien Besancenot, Radu Vranceanu

\section{To cite this version:}

Damien Besancenot, Radu Vranceanu. Fear of novelty: a model of scientific discovery with strategic uncertainty. 2014. hal-01117929

\section{HAL Id: hal-01117929 \\ https://essec.hal.science/hal-01117929}

Preprint submitted on 18 Feb 2015

HAL is a multi-disciplinary open access archive for the deposit and dissemination of scientific research documents, whether they are published or not. The documents may come from teaching and research institutions in France or abroad, or from public or private research centers.
L'archive ouverte pluridisciplinaire HAL, est destinée au dépôt et à la diffusion de documents scientifiques de niveau recherche, publiés ou non, émanant des établissements d'enseignement et de recherche français ou étrangers, des laboratoires publics ou privés. 


\title{
FEAR OF NOVELTY: A MODEL OF SCIENTIFIC DISCOVERY WITH STRATEGIC UNCERTAINTY
}

\author{
RESEARCH CENTER \\ ESSEC Working Paper 1503
}

2015

Damien Besancenot

Radu Vranceanu

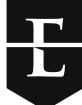


December 26, 2014

\title{
FEAR OF NOVELTY: A MODEL OF SCIENTIFIC DISCOVERY WITH STRATEGIC UNCERTAINTY \\ Damien Besancenot* and Radu Vranceanu ${ }^{\dagger}$
}

\begin{abstract}
This paper analyzes the production of fundamental research as a coordination game played by scholars. In the model, scholars decide to adopt a new idea only if they believe that a critical mass of peers is following a similar research strategy. If researchers observe only a noisy idiosyncratic signal of the true scientific potential of a new idea, we show that the game presents a single threshold equilibrium. In this environment, fundamental research proceeds with large structural breaks followed by long periods of time in which new ideas are unsuccessful. The likelihood of a new idea emerging depends on various parameters, including the rewards of working in the old paradigm, the critical mass of researchers required to create a new school of thought and scholars' ability to properly assess the scientific value of new ideas.
\end{abstract}

Keywords: Economics of science, Scientific discovery, Strategic complementarity, Strategic uncertainty, Global games.

JEL Classification: O31; C72; A14.

\footnotetext{
*University of Paris 13 and CEPN. 93430 Villetaneuse, France. E-mail: besancenot.damien@univ-paris13.fr

${ }^{\dagger}$ Corresponding author. ESSEC Business School and THEMA. 95012 Cergy, France. E-mail: vranceanu@essec.fr.
} 


\section{Introduction}

Fundamental research frequently progresses in a discontinuous manner, with structural breaks driven by major innovations that are followed by long periods of exploitation of the results of such structural breaks (Bramoullé and Saint-Paul, 2010). In his masterpiece, The Structure of Scientific Revolutions, Thomas Kuhn (1962) offers substantial historical evidence that demonstrates that established research paradigms prove to be extremely resilient and that only the inadvertent emergence of critical anomalies can generate paradigm change. ${ }^{1}$ Indeed, many good ideas, that is ideas with scientific value higher than the research produced in the existing paradigm, fail to be implemented or take an abnormal long period of time to be recognized as such. In the "small world of economics", Gans and Sheppard (1994) provide evidence about the high rejection rates and unbelievable delays in publication of papers that are now considered as cornerstones of modern economics. In the opposite direction, Gardner (1957), Stephan (1996), Diamond (1996) and Abrahamson (2009) point out the emergence of fads and fashions in science, where scholars rush on developing ideas that ultimately prove to be sterile.

This paper aims to provide an explanation for these "bumpy" output trajectories in fundamental research by accounting for the coordination risk perceived by researchers considering whether to pursue or adopt a new idea. In scientific research, the scholar exposes his findings to a large community of peers, and takes the challenge of being judged and criticized by them. Yet humans fear criticism and peer rejection. They can hedge against this risk by following the heard, a psychological bias emphasized by Keynes (1936: 158), who noticed

\footnotetext{
${ }^{1}$ As key examples, Kuhn discusses the discovery of oxygen in the late XVIIIth century, the discovery of $\mathrm{X}$-rays, and the discovery of the Leyden jar.
} 
that "worldly wisdom teaches that it is better for reputation to fail conventionally than to succeed unconventionally". ${ }^{2}$ Sociologists of science have argued that success of a new idea depends on whether it will manage or not to generate a sufficiently large degree of consensus (Shwed and Bearman, 2010). Taking this logic one step further, a new idea will reach the "science status" only if a critical mass of researchers adopt it, then test, extend, and develop applications of that idea. Given that research programs are typically confidential (Bobtcheff et al. 2013), a researcher will decide to develop a new idea only if he believes that a sufficient number of researchers are following the same research strategy. Knowledge of the belief formation mechanism is thus fundamental to gaining a deeper understanding of the idea adoption mechanism.

In this context, the researcher's problem can be analyzed as a typical coordination game with strategic complementarities. With complete information and identical players, such games present multiple equilibria; optimal actions are motivated by beliefs, and equilibrium beliefs are correct, but beliefs are ultimately undetermined, which generates the multiplicity of equilibria (Morris and Shin, 2001; 2004). Carlsson and Van Damme (1993) proved that this indeterminacy can be removed in a two-person game if players observe only a biased signal of the variable defining the state of the economy. In this case, individuals should consider not only their own assessment of the economy but also the possible beliefs that the other player may hold regarding the same state of the economy. These authors showed that this type of game in which beliefs are no longer common knowledge presents a unique equilibrium of a particular form: there is a critical state of the economy above which both players

\footnotetext{
${ }^{2}$ The citation is reported by Diamond (1996) in his analysis of the emergence of fads in science.
} 
take the high-risk high-yield strategy and below which they adopt the opposite wait-andsee strategy. Morris and Shin $(1998,2001)$ extended this analysis to n-player coordination games in which each player obtains an idiosyncratic signal regarding the underlying state of the economy. If the private signal is sufficiently precise, then this "global game" also presents a single threshold equilibrium in which players follow an equilibrium "switching strategy". An impressive body of financial economics literature has applied this equilibrium concept to a variety of issues, including bank runs, corporate and public debt illiquidity, credit risk, and currency attacks, among others. ${ }^{3}$

Global games methodology can provide an interesting explanation for the emergence of new fields of research, because it allows to address the coordination problems of scholars whose efforts are rewarded only if the consensus is ultimately reached. In general, new ideas have their own scientific value, related to the benefits society can get from its successful implementation. The model assumes that during any time period, nature draws one new idea from a known statistical distribution of scientific values. The key assumption is that researchers observe only a biased signal of the true scientific potential of any new idea. This idiosyncratic bias is also distributed across scholars, and is related to their own education, experience and personality presenting a different degree of scientific skepticism. Given this individual-specific signal, researchers must choose between continuing their work in the existing paradigm and obtaining safe but modest payoffs or taking risks with the aim of developing a new idea. The new idea will create a successful field of research (a new paradigm) only if a critical mass of researchers simultaneously decides to adopt the idea. If this critical

\footnotetext{
${ }^{3}$ See, for instance: Hellwig (2002), Morris and Shin (2004, 2009), Angeletos and Werning (2006), Angeletos et al. (2007), Metz (2011). See Jorge and Rochas (2014) for a survey.
} 
mass is reached, then the rewards of adopting the new idea depend on its scientific value; conversely, if critical mass is not reached, then the scholar who has spent time developing the new idea will not recover his investment. In this paper, we show that there is an equilibrium cutoff scientific value above which a new strand of research is created and below which the new strand fails to emerge. This result can explain the observed stair-step pattern of scientific discovery without any additional assumptions regarding researcher heterogeneity such as individual-specific preferences. It also provides a rationale for the emergence of fads in science in times of major scientific uncertainty.

Our analysis focuses on one representative stage of a repeated game. In our model, scholars do not improve their ability to assess the true scientific value of a new idea from one period to another. The assumption of a limited learning ability is quite plausible in the realm of scientific research, where often new theories will "toll the bell" of incumbent ones. A more complex model would introduce two generations of scholars, "young" and "old", and consider that experienced scholars might have a different ability to recognize "true science" than the young ones. But whether experienced scholars have a better or worse ability to detect original research, this question is open to debate. In Kuhn's (1962) views, experienced scholars are sometimes too close to the old paradigm and would resist adopting new ideas. Should this be the case, they would not behave as Bayesian learning agents. ${ }^{4}$

One criticism to Morris and Shin's $(1998,2001)$ main result on the uniqueness of the "threshold equilibrium" was raised by Atkeson (2000), followed by Angeletos and Werning (2006). They showed that once asset prices are introduced in the model, the multiplicity of

\footnotetext{
${ }^{4}$ See Angeletos and Werning (2007) for a dynamic global game with learning about the distribution of signals.
} 
equilibria specific to games with complete information reappears. Our analysis is insulated from this type of criticism, since there is no stricto-sensu market for scientific ideas which are freely disseminated.

Thus our analysis can be seen as a contribution to the theoretical literature on the choice, dynamics and success of research programs, one important subfield in the economics of science (Diamond, 1996). Among the most relevant related papers, Brock and Durlauf (1999) develop a model of theory choice in which scholars not only care about their private assessment of the scientific value of the theory, but also are subject to conformism, i.e., they prefer to embrace ideas similar to ideas adopted by others. Their analysis provides a solid explanation for why fundamental research frequently moves from extended disagreement to extended consensus. In a similar vein, Bramoullé and Saint-Paul (2010) analyze the dynamics of fundamental research by considering that scientists derive utility from recognition by other scientists; depending on parameters, the dynamics of research either are smoothly increasing or alternate between periods of innovation and periods of exploitation of the results of research. Faria et al. (2011) analyze paradigm depletion as a dynamic game where the paradigm is modelled as a non renewable natural resource; they determine the optimal pace of paradigm exploitation. Barraquer and Tan (2011) introduce a signaling model in which young scholars do not take the risk of working on new ideas and continue to develop obsolete but highly technical ideas simply to demonstrate their skills to future employers. Hopenhayn and Squintani (2011) and Bobtcheff et al. (2013) study the flow of research as the equilibrium of a preemption game in which players' private information stochastically increases over time and in which the value of innovation is uncertain. Besancenot and Dogguy 
(2014) apply the mean field game theory to analyze how scholars' optimal choice of research topics determines paradigm shifts. These authors also acknowledge that the utility of an individual scholar is positively related to the number of scholars who work within his own strand of research.

This paper is organized as follows. The next section introduces the main assumptions. Section 3 solves the model for the equilibrium cutoff scientific value and cutoff signal and performs some comparative statics. The last section presents our conclusions.

\section{Main assumptions}

The analysis distinguishes between "Pioneers", responsible of generating new ideas, and "Normal scholars". We assume that the idea generation process is exogenously given: during any given time period, one such Pioneer launches one new idea, for instance as a published paper. The scientific value of a new idea, which refers to the benefit that the successful implementation of this idea might bring to society, is denoted by $\theta$, with $\theta \in \mathbb{R}$. Observed over a long period of time, $\theta$ appears to be a random variable.

Normal scholars are represented by a unit mass of identical risk-neutral researchers indexed by $i \in[0,1]$. To keep the model as simple as possible, it is assumed that these scholars have diffuse priors on the distribution of scientific values, that is they believe that $\theta \sim \operatorname{unif}(-\infty,+\infty) .{ }^{5}$ These high-skill professionals monitor the publication flow and can detect new ideas. When an original paper emerges, each normal researcher can choose between investing time and effort to develop the high-yield, high-risk new idea as an early adopter,

\footnotetext{
${ }^{5}$ Diffuse priors allow to work with simple formula and present no difficulty as long as we are concerned with conditional beliefs (Metz, 2003; Veldkamp, 2011). The logic of the model would not change if instead of diffuse priors we use another distribution, but the uniqueness of the equilibrium is no longer granted.
} 
or continuing his research activity in the old strand of research, and eventually move to the new idea later on as a follower. Let $\ell$ denote the number of researchers who decide to adopt the new idea in the first place, with $\ell \in[0,1]$.

Consistent with Kuhn (1962), working to develop and extend an existing paradigm (as a "puzzle solver") is a low-risk activity, but the scientific value of such developments is also likely to be relatively modest. We will assume that ideas produced in the old strand of research have a predetermined scientific value equal to $s$, with $s>0$. In line with the consensus-based definition of science, a new strand of research emerges only when a critical mass of scholars decide to develop the new idea. In other words, a new idea will not obtain "science" status if it is not challenged, tested, copied, and applied to various problems and subfields. Let $v$ denote the critical mass of researchers required to create a new strand of research, with $v \in(0,1)$ being known and exogenously given.

A scholar's reward from research may be multi-dimensional (Merton, 1957; Stephan, 1996); a successful research programme might lead to a better position, a better wage, enhanced reputation and social status, more citations, and better media coverage, among other benefits. For purposes of the subsequent analyses, we convert and collapse all these benefits into a single-dimension monetary equivalent. Following Merton (1957), it has been recognized that the highest rewards in science go to Pioneers (not modelled explicitly in our paper), then to early adopters. To acknowledge for this "competitive reward mechanism", we assume that a scholar who continues working in the old paradigm receives a certain payoff of $s$, identical to the social value of the idea. On the other hand, a scholar who decides to develop a new idea as an early adopter will get a payoff equal to the social value of the new 
idea $(\theta)$ if the new strand of research is established $(\ell \geq v)$, or zero if the new strand of research fails to achieve legitimacy $(\ell<v) .{ }^{6}$

In other words, even if the idea is excellent, if no one else is adopting it, the idea will not reach universal recognition, and the value of the research for the researcher will be zero (i.e., the scholar cannot recover his investment in time and effort). On the contrary, if a critical mass of researchers is adopting the idea, then the idea will attain "science" status and will produce a gain that is here assumed to be identical to the scientific value of the idea. A scholar will not choose to work on a new idea if he believes that in case of success of the idea his reward will be lower than working in the old strand of research. These beliefs depend on the signal he observes, given the quality of the signals. Given our assumption on the distribution of $\theta$, we cannot rule out the theoretical possibility that in some special conditions (to be defined later on), a very poor idea $(\theta<0)$ can originate a strand of "pseudoscience". Our payoff structure tells us that if one scholar works on a poor idea but the idea does not become visible, his payoff is zero. Yet, if enough scholars work on developing a poor idea and manage to create a "pseudo-science", their reward should be in line with the reputation from developing an absurd research domain. ${ }^{7}$

\footnotetext{
6 This linear payoff function implicitly assumes that the private value of a scientific research (for the scholar) is identical to its social value. It must be acknowledged that in some cases, private and social value of scientific discovery might diverge.

${ }^{7}$ If we want to rule out the emergence of pseudo-sciences and consider that all ideas have positive scientific value, we could alternatively assume that $\theta \sim$ unif $[0,+\infty)$.
} 
In sum, the payoff $u_{i}$ of a scholar $i \in[0,1]$ has the following structure:

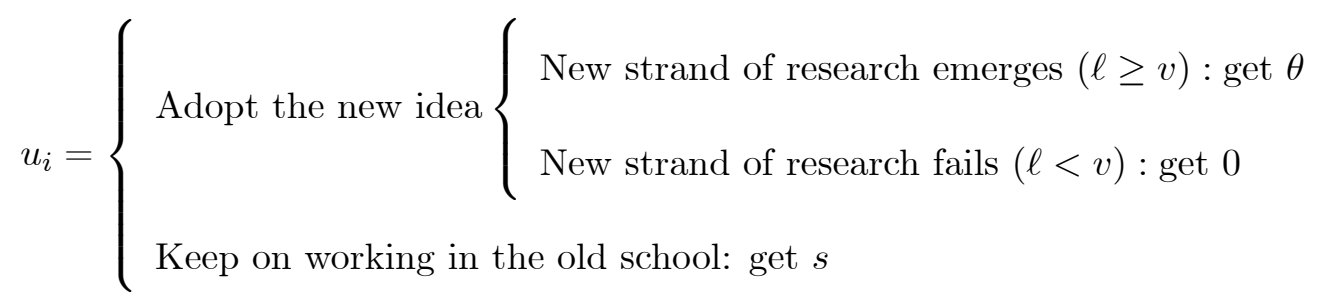

Notice that at the next stage of the game, the same "static" decision replicates identically. If a new strand of research emerges at period $t$, in $t+1$ it will become "old", and will deliver the payoff $s$ both to early adopters and followers.

If $\theta$ is common knowledge and larger than $s$, then the scholars' coordination game presents two trivial Nash equilibria. The first is the Pareto-dominant equilibrium in which all researchers participate in the new program of research: because $\ell=1>v$, the new topic emerges as a new paradigm, and each scholar receives $\theta>s$. Thus, a researcher who chooses to work in the old paradigm would regret his choice. Because the gain of each researcher ultimately depends on the decisions of others, this equilibrium involves a form of coordination risk. The second equilibrium is the zero-risk, Pareto-dominated equilibrium in which all researchers continue working in the old paradigm and receive the meagre but certain $s$; because $\ell=0<v$, the new paradigm does not emerge. If only one researcher decides to pursue the new field of research, his contribution alone is insufficient to allow the topic to generate a new field of research, and he would regret his choice $(0<s)$. This is a typical multiple equilibria configuration: which of the two equilibria actually prevails depends on scholars' beliefs, but these beliefs are undetermined by the model.

However, in the world of research, there is a strong element of subjectivity in assessing the scientific potential of a new idea. It is realistic to assume that each time a new idea emerges, individual scholars observe only a noisy signal of the underlying scientific potential. 
This bias is related to the education and scientific personality of the scholars, which, as all human beings, are different. More precisely, let each scholar $i \in[0,1]$ observe the following signal:

$$
x_{i}=\theta+\varepsilon_{i},
$$

where the bias $\varepsilon_{i} \sim$ unif $[-\epsilon,+\epsilon]$. In other words, the distribution of signals in the population of scholars is centered around $\theta$, with $x_{i} \sim$ unif $[(\theta-\epsilon),(\theta+\epsilon)]$.

In this case, beliefs are no longer common knowledge, and the problem has all the features of a standard n-player global game as studied and solved for equilibrium by Morris and Shin (1998, 2001). With this information structure, a researcher with a "skeptical assessment" $\left(\varepsilon_{i}<0\right)$ would not pay much attention to an idea with high scientific potential, whereas, conversely, a researcher with an "enthusiastic assessment" $\left(\varepsilon_{i}>0\right)$ may decide to adopt a rather weak new idea.

\section{The threshold equilibrium}

Following the resolution steps indicated by Atkeson (2001), we define the cutoff scientific value $\theta^{*}$ (the state variable) such that:

$$
\left\{\begin{array}{l}
\text { for } \theta \geq \theta^{*} \text { the new strand of research emerges }(\ell \geq v) \\
\text { for } \theta<\theta^{*} \text { the new strand of research fails to to take-off }(\ell<v)
\end{array} .\right.
$$

In relation to the cutoff state variable, there is a critical signal $x^{*}$, such that:

$$
\left\{\begin{array}{l}
\text { for } x \geq x^{*} \text { the scholar prefers to develop the new idea } \\
\text { for } x<x^{*} \text { the scholar prefers to work on the safe old topic }
\end{array}\right.
$$

The equilibrium is thus characterized by the couple $\left(\theta^{*}, x^{*}\right)$ and by scholars' optimal strategies connected to these thresholds. 
a/ We can first analyze how $\theta^{*}$ is determined, for a predetermined critical signal $x^{*}$.

As already mentioned, when a new idea with a scientific value $\theta$ is published, the distribution of signals in the population of scholars $x_{i}$ has mean $\theta$. All scholars with $x_{i}>x^{*}$ will adopt the new idea. For the time being we consider that the critical signal $x^{*}$ is predetermined. The number of scholars who decide to develop the new idea is:

$$
\ell(\theta)=1-\operatorname{Pr}\left[x_{i} \leq x^{*} \mid \theta\right]
$$

where:

$$
\operatorname{Pr}\left[x_{i} \leq x^{*} \mid \theta\right]=\left\{\begin{array}{l}
\frac{x^{*}-\theta+\epsilon}{2 \epsilon} \text { for } x^{*} \in[(\theta-\epsilon),(\theta+\epsilon)] \\
0 \text { for } x^{*}<(\theta-\epsilon) \\
1 \text { for } x^{*}>(\theta+\epsilon)
\end{array} .\right.
$$

All other things equal, the number of scholars who decide to adopt the new idea increases with the (unobserved) scientific value of the idea, $\theta$. Since the probability $\operatorname{Pr}\left[x_{i} \leq x^{*} \mid \theta\right]$ varies between 0 and 1 depending on $\theta$, there is a cutoff scientific value $\theta^{*}$, such that for $\theta>\theta^{*}$, we have $\ell(\theta)>v$ (the strand of research emerges), and for $\theta<\theta^{*}$, we have $\ell(\theta)<v$ (the new strand fails). This cutoff scientific value $\theta^{*}$ is implicitly defined by:

$$
\ell\left(\theta^{*}\right)=v \Leftrightarrow 1-\frac{x^{*}-\theta^{*}+\epsilon}{2 \epsilon}=v
$$

or, in an equivalent way, as:

$$
x^{*}-\theta^{*}=\epsilon(1-2 v) \text {. }
$$

b/ We then study how $x^{*}$ is determined, considering that nature has drawn precisely the cutoff scientific value, $\theta^{*}$ (which is, for the time being, assumed to be predetermined).

The scholar assesses the probability that the new idea fails $\left(\operatorname{Pr}\left[\theta<\theta^{*}\right]\right)$ by considering the distribution of $\theta$ after observing the signal $x_{i}$. Given that the ex-ante distribution of 
$\theta$ is diffuse and that the bias is uniformly distributed around the realized $\theta$, its ex-post distribution is uniform too: $\theta \mid x_{i} \rightsquigarrow \operatorname{unif}\left[\left(x_{i}-\epsilon\right),\left(x_{i}+\epsilon\right)\right] .^{8}$

Given the definition of the threshold $\theta^{*}$, for $\theta<\theta^{*}$, the payoff of the scholar who adopts the new idea is 0 , and for $\theta>\theta^{*}$, his payoff is $\theta$. We define the expected payoff of a scholar $i$, who observes a signal $x_{i}$ and chooses to adopt (A) the new idea by $E^{A}\left[u_{i} \mid x_{i}\right]$.

$$
\begin{aligned}
E^{A}\left[u_{i} \mid x_{i}\right] & =\int_{\theta^{*}}^{+\infty} \theta f\left(\theta \mid x_{i}\right) d \theta=\frac{1}{2 \epsilon} \int_{\theta^{*}}^{x_{i}+\epsilon} \theta d \theta=\frac{1}{4 \epsilon}\left[\theta^{2}\right]_{\theta^{*}}^{x_{i}+\epsilon} \\
& =\frac{1}{4 \epsilon}\left[\left(x_{i}+\epsilon\right)^{2}-\left(\theta^{*}\right)^{2}\right]=\frac{\left(x_{i}+\epsilon+\theta^{*}\right)\left(x_{i}+\epsilon-\theta^{*}\right)}{4 \epsilon}
\end{aligned}
$$

The expected gain is an increasing function in the signal $x_{i} \cdot{ }^{9}$

Among the mass of scholars, there is one who is indifferent between working in the new field or keeping with the old one. Let his signal be $x^{*}$. It is implicitly defined by:

$$
E^{A}\left[u \mid x^{*}\right]=s \Leftrightarrow \frac{\left(x^{*}+\epsilon+\theta^{*}\right)\left(x^{*}+\epsilon-\theta^{*}\right)}{4 \epsilon}=s .
$$

If a scholar has a signal $x_{i}>x^{*}$, he will adopt the new idea, if not he will continue to develop the old paradigm. Equation (7) indeed defines the cutoff signal.

c/ The system of equations (5) and (7) can be solved for the equilibrium cutoffs:

$$
\theta^{*}=\frac{s}{1-v}-(1-v) \epsilon
$$

and:

$$
x^{*}=\frac{s}{1-v}-v \epsilon .
$$

\footnotetext{
8 In the alternative specification where $\theta \sim$ unif $[0,+\infty)$, the ex-post distribution of $\theta$ is $\theta \mid x_{i} \sim$ unif $\left[\max \left(0, x_{i}-\epsilon\right),+\infty\right)$. We obtain the same solution as for the distribution analyzed in the text for $\epsilon<s /\left(1-v^{2}\right)$.

${ }^{9}$ For $x_{i}>-\epsilon$. It can be checked latter on that the condition holds for the equilibrium $x^{*}$.
} 
It can be seen that, under the assumption of uniformly distributed $\theta$ and $\epsilon$, the problem presents a single threshold equilibrium, whatever the precision of the signal.

If the quality of the signal is good enough $\left(\epsilon<\frac{s v}{(1-v)^{2}}\right)$, then the equilibrium threshold $\theta^{*}$ is larger than $s$. This outcome has an interesting interpretation: in a decentralized research organization, some "good ideas" (that is, ideas that have a scientific value that is greater than the value of the old ideas $\left.\left(\theta \in\left[s, \theta^{*}\right]\right)\right)$ might be rejected because of strategic uncertainty. If $\theta \in\left[s, \theta^{*}\right]$, scholars behave as if they "fear novelty"; in fact, their excessive cautiousness is an equilibrium outcome as they rationally infer that the critical mass cannot be reached.

Notice that in the special case where $\epsilon \rightarrow 0$, that is when the precision of the signal is almost perfect, the two equilibrium cutoffs become:

$$
\theta^{*}=x^{*}=\frac{s}{1-v}>s .
$$

To sum up, in a scientific environment characterized by a relatively small level of noise in the perception of the true scientific value of new ideas, some good ideas will never be implemented.

On the other hand, scientific discovery was often subject to fads, where scholars massively rush to develop an idea that ultimately proves to be completely wrong (Gardner, 1957; Stephan, 1996; Abrahamson, 2009). In our model, if the quality of the signal is poor enough $\left(\epsilon>\frac{s v}{(1-v)^{2}}\right)$, then the equilibrium threshold $\theta^{*}$ is lower than $s$. This means that in a state of strong scientific uncertainty some "poor" ideas, that is ideas with a lower scientific value than applications brought by the existing paradigm $\left(\theta \in\left[\theta^{*}, s,\right]\right)$, might lead to the emergence of a new strand of research. Moreover, if uncertainty is very high (and $v$ is small), even ideas with a negative scientific value might be followed. 
It can be reasonably assumed that in science scholars face substantial uncertainty $(\epsilon$ is large). Yet, whether the equilibrium is characterized by $\theta^{*}>s$ (fear of novelty) or by $\theta^{*}<s$ (fads), it depends to a large extent on the critical mass $v$. If $v$ is large, then chances that the first situation prevails are high.

The analysis of the equilibrium allows us to perform some elements of comparative statics. In the line of Kuhn (1962), Faria et al. (2011) argued that the capacity of an incumbent paradigm to produce a flow of applications and developments can gradually fade away. In our model, when the scientific contribution of the old school of thought decreases $(d s<0)$, then the equilibrium cutoff $\left(\theta^{*}\right)$ declines, and the likelihood that a new idea will initiate a new school of thought, eventually replacing the old paradigm, should increase. ${ }^{10}$ In a more powerful model, with repeated interactions, we can imagine that once a new idea is adapted, the initial value of developing it is so high that the likelihood to get a much better one is quite low. But over time it gets harder and harder to get results from the current idea, so the threshold in equilibrium gets lower and lower, and another new idea can find its way out. ${ }^{11}$

If the critical mass of researchers required for a new paradigm to emerge decreases $(d v<$ $0)$, then $\theta^{*}$ also declines, and the likelihood that a new idea will initiate new school of thought increases. Advances in research dissemination prompted by the development of the Internet (e.g., new journals and new open-access communication channels) have significantly increased the accessibility of scientific research in the last twenty years (Besancenot and Vranceanu, 2014). These technological changes, if they allow for more rapid and efficient

\footnotetext{
10 This effect might be offset by a mechanism that is not outlined in our model, related to the inertia of researchers that have invested too much in the old paradigm.

${ }^{11}$ In such a repeated interaction model, we can consider that at $t+1$ the old paradigm delivers $s_{t+1}=\delta \theta_{t}$, where $\delta<1$ stands for a decay rate.
} 
dissemination and access to research, can support a reduction in the critical mass required for a new research program to achieve legitimacy. In this case, we can foresee an acceleration of the pace of adoption of new ideas, likely with a lower average scientific value.

\section{Conclusion}

The evolution of fundamental research frequently proceeds by means of major innovations followed by long periods dedicated to the exploitation of results, during which time new ideas fail to be launched. Several analyses have explained this pattern of scientific discovery by scholars' preference for "conformity", in which researchers prefer to work within fields that are not very far from the work of their peers (Brock and Durlauf, 1999; Bramoullé and SaintPaul, 2010). This paper provides an original explanation for this phenomenon that builds on the methodology of coordination games with strategic complementarity and uncertainty regarding the information structure, which are better known as "global games" (Carlsson and Van Damme, 1993; Morris and Shin, 1998; 2001). In this context, observed conformity appears as the natural consequence of scholars' aversion to strategic uncertainty.

In our model, the scientific value of new ideas is represented as a random variable with a known statistical distribution. During each time period, a new idea emerges, and scholars observe its scientific value (only) as a noisy signal. Our analysis has focused on the representative stage of a repeated game with no learning across stages, thus with an invariant statistical distribution of signals. Also, in our simplified model, the scholar's payoff was assumed to be a linear function in the social value of a collectively adopted idea. Thus the model abstracts from possible divergences between the private and social value of scientific discoveries. Further research could address these important questions. 
Under general statistical distributions of the state variable and signal noise, Morris and Shin $(1998,2001)$ have shown that n-player global games can present no equilibrium, one equilibrium or multiple equilibria. In general, it has been shown that such games presents a single threshold equilibrium if private signals are sufficiently precise. In our paper, we make the assumption of an uniformly distributed state variable and noise, and show that the equilibrium is unique, whatever the variance of the signal. We then determine the equilibrium cutoff scientific value above which a critical mass of scholars adopt the new idea (which leads to the creation of a new school of thought) and below which they do not. It the precision of the signal is high enough, this equilibrium cutoff scientific value is greater than the scientific value of the ideas produced in the old paradigm. This finding is troubling because it indicates that some good ideas will not be implemented simply because scholars take into account the strategic coordination risk and behave as if they "fear novelty". To the contrary, if the precision of the signal is low, the model explains why poor ideas are occasionally developed and even followed for a long period, what was referred to as a fad in science.

According to our model, such inefficiencies would appear as by-product of the decentralized organization of research; to be sure, research competition specific to such an environment can also result in important benefits, such as greater effort intensity, but this model cannot account for such positive spillover, unfortunately. Furthermore, in many areas, the existing organization of research is characterized by large research institutions staffed with hundreds of researchers and national funding agencies who set the research agenda for the field. Given the size of such institutions, if they decide to launch a new research program, then the critical mass of scholars can be reached with certainty, and individual researchers need not fear the 
coordination risk. Researchers should thus choose to work on that research topic, provided that they perceive an expected reward that is larger than $s$. Unfortunately, if the large institution selects a poor idea (with a small or even negative $\theta$ ), it would then be responsible for the emergence of a strand of research with modest scientific value. As an example, Diamond (1996) recalls Milton Friedman's criticism of the US National Science Foundation, which, in his opinion, has directed the economics profession toward a highly mathematical model. ${ }^{12}$

Coordination of efforts and investments is a critical requirement for the success of any research programme or mission. Ideas developed in this paper suggest that global games might provide a suitable methodology to analyze a broader range of problems in the economics of science.

\section{References}

Abrahamson, E., 2009. Necessary conditions for the study of fads and fashions in science, Scandinavian Journal of Management, 25 (2), pp. 235-239.

Angeletos, G. M., and Werning, I., 2006. Crises and prices: Information aggregation, multiplicity, and volatility, American Economic Review, 96 (5), pp. 1720-1736.

Angeletos, G. M., Hellwig, C., and Pavan, A., 2007. Dynamic global games of regime change: Learning, multiplicity, and the timing of attacks, Econometrica, 75 (3), pp. 711-756.

Atkeson, A. A., 2001. Comment on Morris and Shin: Rethinking multiple equilibria in macroeconomic modeling, NBER Macroeconomics Annual 2000, Vol. 15, pp. 162-171.

Barraquer, T. R., and Tan, X., 2011. Conspicuous scholarship: Competitive unraveling in the choice of research topics, mimeo, Hebrew University of Jerusalem and Stanford University.

Besancenot, D., and Dogguy, H., 2014. Paradigm shift: a mean field game approach, Bulletin of Economic Research, http://onlinelibrary.wiley.com/doi/10.1111/boer.12024.

Besancenot, D., and Vranceanu, R., 2014. A model of scholarly publishing with hybrid academic journals, ESSEC Working Paper 1406.

\footnotetext{
12 Ironically, his opinion is endorsed in this paper by a "highly mathematical model".
} 
Bobtcheff, C., J. Bolte, and Mariotti, T., 2013. Researcher's dilemma. Institut d'Économie Industrielle Toulouse, IDEI Working Paper 763.

Bramoullé, Y., and Saint-Paul, G., 2010. Research cycles, Journal of Economic Theory, 145 (5), pp. 1890-1920.

Brock, W. A., and Durlauf, S. N., 1999. A formal model of theory choice in science, Economic Theory, 14 (1), pp. 113-130.

Carlsson, H. and Van Damme, E., 1993. Global games and equilibrium selection, Econometrica, 61 (5), pp. 989-1018.

Faria, J. R., Besancenot, D., and Novak, A. J., 2011. Paradigm depletion, knowledge production and research effort: Considering Thomas Kuhn's ideas. Metroeconomica, 62 (4), pp. 587-604.

Diamond, A. M., 1996, The Economics of Science, Knowledge and Policy, 9 (2-3), pp. 6-49.

Gardner, M., 1957, Fads and Fallacies in the Name of Science. Courier Dover Publications.

Hellwig, C., 2002. Public information, private information, and the multiplicity of equilibria in coordination games, Journal of Economic Theory, 107 (2), pp. 191-222.

Hopenhayn, H. A., and Squintani, F., 2011. Preemption games with private information, Review of Economic Studies, 78 (2), pp. 667-692.

Jorge J., and Rocha, J., 2014. A primer on global games applied to macroeconomics and finance, Journal of Economic Surveys, forthcoming, doi: 10.1111/joes.12071.

Keynes, J. M., 1936, The General Theory of Employment, Interest and Money, In: Volume 7 of The Collected Writings of J.M. Keynes, 1973, MacMillan, London.

Kuhn, T.S., 1962. The Structure of Scientific Revolutions, University of Chicago Press, Chicago.

Merton, R K., 1957. Priorities in scientific discovery: a chapter in the sociology of science, American Sociological Review, 22 (6), pp. 635-659.

Metz, C. E., 2002, Private and public information in self-fulfilling currency crises, Journal of Economics 76, 1, pp. 65-85.

Morris, S., and Shin, H. S., 1998. Unique equilibrium in a model of self-fulfilling currency attacks, American Economic Review, 88 (3), pp. 587-597.

Morris, S., and Shin, H. S., 2004. Coordination risk and the price of debt, European Economic Review, 48 (1), pp. 133-153.

Morris, S., and Shin, H. S., 2001. Rethinking multiple equilibria in macroeconomic modeling, NBER Macroeconomics Annual 2000, Vol. 15, pp. 139-161. 
Morris, S., and Shin, H. S., 2009. Illiquidity component of credit risk, Working Paper Princeton University.

Shwed, U., and P. S. Bearman, 2010. The temporal structure of scientific consensus formation, American Sociological Review 75, (6), pp. 817-840.

Stephan, P.E., 1996. The economics of science, Journal of Economic Literature, 34, pp. 1199-1235.

Veldkamp, L. L., 2011. Information choice in macroeconomics and finance. Princeton University Press. 


\section{ESSEC Business School}

Avenue Bernard Hirsch

CS 50105 Cergy

95021 Cergy-Pontoise Cedex

France

Tél. + 33 (0) 134433000

Fax +33(0)134433001

www.essec.fr

ESSEC Executive Education

CNIT BP 230

92053 Paris-La Défense

France

Tél. + 33 (0)1 46924900

Fax +33(0)1 46924990

www.executive-education.essec.fr

\section{Contact:}

ESSEC Asia-Pacific

100 Victoria Street

National Library \# 13-02

Singapore 188064

Têl. +65 68849780

Fax +6568849781

www.essec.edu/asia

Research Center +33 (0)134433358 research.center@essec.fr

\section{a}

